\title{
Role of circular RNAs and long non-coding RNAs in the clinical translation of gastric cancer (Review)
}

\author{
BO CAO $^{1 *}$, GUOXIAO LIU $^{1 *}$, WANG ZHANG $^{1}$, YAJIAO SHI $^{2}$ and BO WEI ${ }^{1}$ \\ ${ }^{1}$ Department of General Surgery, Chinese PLA General Hospital, Beijing 100853; \\ ${ }^{2}$ Medical School, Guizhou University, Guiyang, Guizhou 550025, P.R. China
}

Received May 22, 2020; Accepted October 14, 2020

DOI: $10.3892 / \mathrm{ijmm} .2020 .4774$

\begin{abstract}
Gastric cancer (GC) is a malignancy with high incidence and mortality rates worldwide. It has a severe impact on patients diagnosed and on society. With the rapid development of bioinformatics and detection technologies, non-coding RNAs have been demonstrated to play important roles in gastric carcinogenesis, including circular RNAs (circRNAs) and long non-coding RNAs (IncRNAs). Previous studies have indicated that these two types of RNAs with notable characteristics can serve as promising biomarkers for clinical diagnosis and prognosis. The identification of relevant mechanisms has revealed the immense potential of circRNAs and lncRNAs in the treatment of GC. However, there are still numerous issues that need to be resolved. The present review focuses on the clinical translation of circRNAs and lncRNAs into GC. Important achievements and currently existing limitations in this field of research are summarized from recent studies. The present review also proposes serviceable suggestions for further development.
\end{abstract}

\section{Contents}

1. Introduction

2. Circular RNAs (circRNAs)

3. Long non-coding RNAs (IncRNAs)

4. IncRNAs and circRNAs in exosomes

5. Comparison of achievements regarding circRNAs and lncRNAs

6. Prospects

7. Conclusion

Correspondence to: Dr Bo Wei, Department of General Surgery, Chinese PLA General Hospital, 28 Fuxing Road, Beijing 100853, P.R. China

E-mail: 18431143691@163.com

*Contributed equally

Key words: gastric cancer, circular RNA, long non-coding RNA, diagnosis, prognosis, treatment

\section{Introduction}

Gastric cancer (GC) is one of the most common malignancies worldwide, and is ranked as the fourth most common type of cancer and the third highest cause of cancer-related mortality. Despite a slight decline in incidence, $\sim 1,000,000$ individuals are diagnosed with GC and $>700,000$ patients succumb to the disease each year (1). Surgery remains the main treatment strategy for GC. In recent years, the wide application of neoadjuvant chemoradiotherapy has improved the survival rates and quality of life of patients, and has reduced the chances of a necessary gastrectomy $(2,3)$. If patients are diagnosed with $\mathrm{GC}$ at early stages and receive treatment promptly, then their chances of recovery are optimal. However, the majority of patients are initially diagnosed with GC at an advanced stage due to atypical symptoms and the lack of sensitive examinations (4). Poor prognosis calls for more effective diagnostic methods with improved sensitivity and specificity. There is also a need for developing novel target medicine to enhance the efficacy of cancer treatment and minimize the side-effects of conventional perioperative regimens.

\section{Circular RNAs (circRNAs)}

In 1976, Kolakofsky (5) reported the existence of circRNAs in viroids. Three years later, Hsu and Coca-Prados (6) found a circular form of RNA in the cytoplasm of eukaryotic cells. circRNAs have long been recognized as the product of error splicing $(7,8)$. This hypothesis has been greatly challenged by accumulating evidence $(9,10)$. circRNAs are a new class of unique RNAs with single-stranded, covalently closed and continuous loop structures (11). The mechanisms through which circRNAs are produced are considered to involve the 'back splicing' or 'head-to-tail splicing' of linear RNAs (12). There are two important biological features of circRNAs, including their notable stability and highly conserved sites. Their high stability may be mostly attributable to their closed 3'-5' links structure, which leads to resistance to exonucleases. Indeed, the half-life period of circRNAs is usually $>48 \mathrm{~h}(8,13)$. The other feature is the highly conserved sites of eukaryotic genes, which endows them with more potential for target treatment (14). Existing evidence has indicated four functions of circRNAs: i) circRNAs can serve as microRNA (miRNA or miR) sponges to induce miRNA loss-of-function $(15,16)$; 
ii) circRNAs can regulate the expression of protein-coding genes through RNA binding proteins (17); iii) interaction with RNA polymerase can regulate the expression of parental genes (18); and iv) some circRNAs can play the same role of directly encoding proteins as mRNAs (19) (Fig. 1).

circRNAs have been demonstrated to play an indispensable role in physiological and pathological changes (20-22). In recent years, attention has been paid to the association between circRNAs and cancer. Some circRNAs may participate in the carcinogenesis, progression and metastasis of numerous types of cancer $(9,23,24)$, which suggests that they have potential diagnostic and prognostic value for patients with cancer $(25,26)$. Despite the fact that a relatively small number of studies have been conducted on this topic, circRNAs have already demonstrated their optimal function in the clinical translation of tumors.

Diagnostic and prognostic role of circRNAs in GC. A number of circRNAs were identified serendipitously and were largely disregarded as non-specific byproducts when they were found to be expressed at low levels. Nonetheless, circRNAs appear to be abundant in both normal and cancer cells. Some types of circRNAs are present at levels comparable to those of their canonical linear counterparts. Furthermore, Salzman et al (27) even reported that the abundance of circular molecules exceeded that of associated linear mRNAs by $>10$-fold in some cases. These results suggest that circRNA levels are absolutely detectable. Carcinogenesis and progression may lead to the alteration of circRNA profiles, which can serve as a novel indicator of GC.

The first step in exploring the association of circRNAs with GC is to screen the circRNA profiles of patients with GC and normal individuals. The identification of circRNAs at differential expression levels may contribute to a better understanding of the mechanisms of GC, which also suggests their use as potential biomarkers for diagnosis and prognosis. The existing types of specimens that have been studied include tumor tissues, blood and gastric juices. Previous studies have reported GC expression profiles, and some of them have constructed circRNA-miRNA or circRNA-miRNA-mRNA regulatory networks by bioinformatics analysis (28-31). These results provide fundamental evidence for searching potential targets of circRNAs and potential downstream of RNAs. For instance, Gu et al (29) found that circ_101504 played a central role in the regulatory network. circ_101504 was predicted to affect some mRNAs by inhibiting miR-454-3p and miR-301a-3p. Future studies should be conducted to verify the signaling pathways. Huang et al (30) screened three sets of tissues and found that only circ_0026 was significantly downregulated. Bioinformatics analysis indicated a potential role of circ_0026 in gastric carcinogenesis and its potential use as a diagnostic biomarker. Despite the limited number of GC samples, that study provided a direction of research points (30).

Numerous studies have indicated the potential diagnostic values of circRNAs in GC. The majority of these have focused on altered circRNA expression levels in GC and adjacent tissues. The area under the curve (AUC) of a ROC curve is a comprehensive indicator of diagnostic values. Previous studies have revealed that circ_0001017 has the highest diagnostic accuracy in tissues, with an AUC of 0.871 .
The sensitivity and specificity could reach, respectively, 79.4 and $81.1 \%$ (32). Li et al (33) demonstrated that the downregulation of circ_002059 had a potential diagnostic value in GC, with its AUC being 0.73. Its sensitivity and specificity were, respectively, 0.81 and 0.62 . Samples stored at various temperatures for different periods of time exhibited the same expression levels of circ_002059, which demonstrated its optimal stability as a clinical biomarker (33). circ_0000190 was previously demonstrated to be downregulated in GC tissues, and had a higher AUC (0.75), than that of circ_002059 (34). Tian et al (35) found that circ_0003159 could also become a potential GC biomarker. The AUC, sensitivity and specificity were $0.75,0.852$ and 0.565 , respectively. As far as circ_0074362 is concerned, despite its low sensitivity and specificity, the levels of circ_0074362 have been shown to be closely associated with lymphatic metastasis, suggesting it may be an auxiliary biomarker for predicting the advancement of GC (36).

Some researchers have noted the clinical value of circRNAs in plasma. Previously, the circ_0000745 expression level in plasma was assessed, and its sensitivity reached 0.855 . However, the current diagnostic use of circ_0000745 cannot meet clinical standards due to its relatively low specificity (37). The ubiquitous expression of circRNAs can be regarded as the main reason behind this low specificity. The accuracy of circRNAs in tissues is commonly higher than that in plasma partly due to spatial position. Notably, Sun et al (38) reported that the diagnostic accuracy of circ_0000520 was much higher than the one in tumor tissues. The AUC, sensitivity and specificity were 0.8967 , 0.8235 and 0.8444 , respectively. According to the aforementioned studies, the diagnosis of a single circRNA does not meet clinical translation. Li et al (32) combined the four biomarkers (circ_0001017 and circ_0061276 both in tissues and in plasma) as a panel. The sensitivity and specificity were 95.5 and $95.7 \%$, respectively. Thus, the circRNA panel is regarded as the most promising for possible and effective translation into clinical application.

The detection of circRNAs in gastric juice is another potential non-invasive type of clinical examination. Shao et al (39) recruited 38 healthy volunteers, 30 patients with gastric ulcer, 15 patients with chronic atrophic gastritis and 39 patients with GC in order to evaluate the diagnostic values of circ_0014717. Although no significant differences in circ_0014717 levels were observed amongst the healthy, gastric ulcer and GC groups, a marked reduction was observed in the chronic atrophic gastritis group. Chronic atrophic gastritis is a possible precancerous lesion of GC (40); thus, the aforementioned study suggested that circ_0014717 may be a predictive indicator of GC. This result broadens the horizons that circRNAs can exist in an extreme environment for a long period of time. Their considerable stability suggests that circRNAs are likely to become an excellent non-invasive biomarker for GC.

Accumulating evidence has demonstrated that circRNAs may play a promising role in predicting the prognosis of GC. A common method used for the prognosis of GC is defining the cut-off value of circRNAs. Recruited patients can be divided into positive (high expression) and negative (low expression) groups. Kaplan-Meier survival analysis is then employed to evaluate the association between circRNAs 


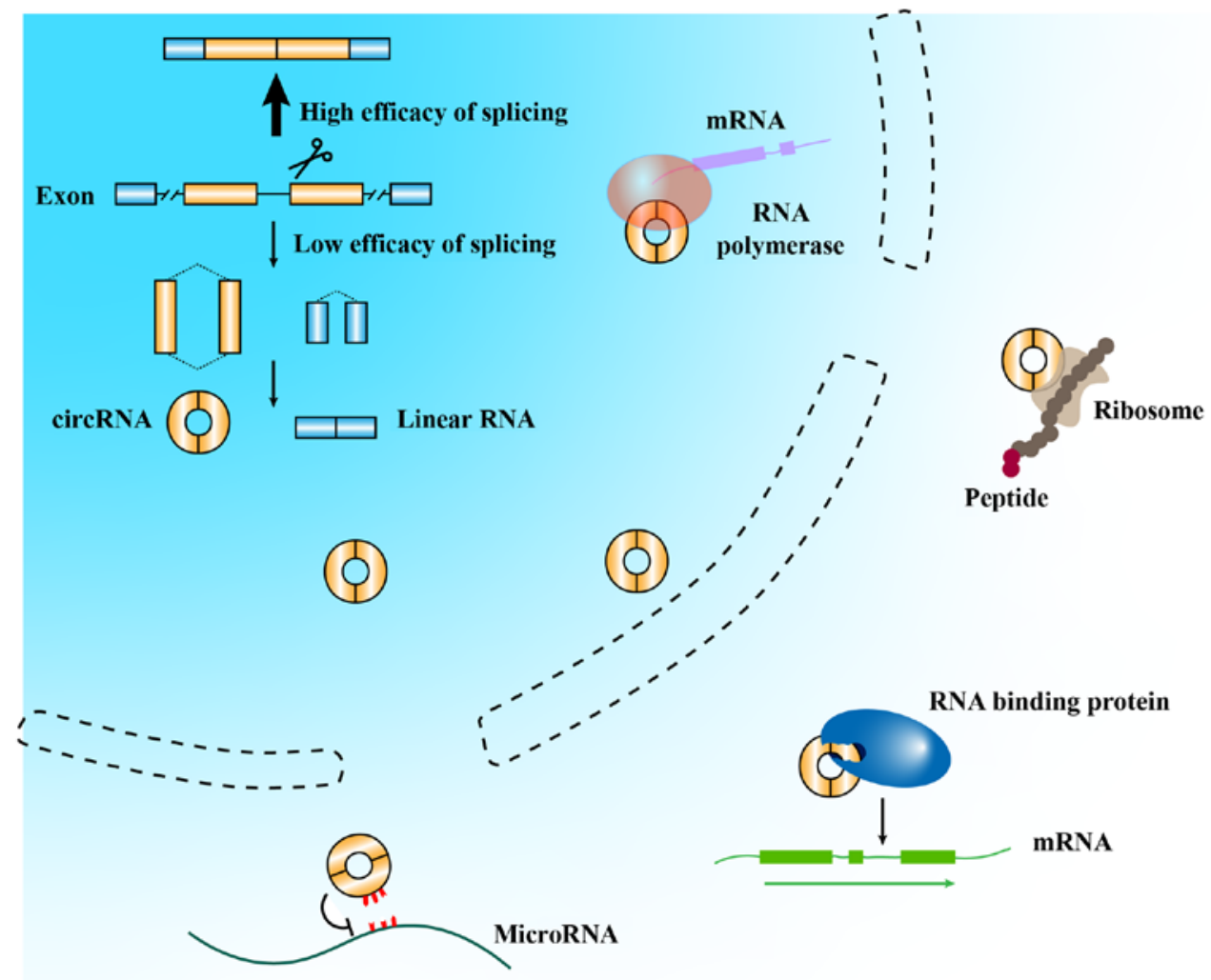

Figure 1. Biological functions of circRNAs. In the nucleus, mRNA precursors can be spliced with high efficiency, producing linear RNAs that contains exons. Comparably, precursors can go through back-splicing and generate circRNAs with low efficiency. The circRNAs can be transferred into the cytoplasm or continue to function in the nucleus. Based on current studies (15-19), the functions of circRNAs can be concluded into four aspects: i) circRNAs can serve as miRNA sponges to induce miRNA loss-of-function; ii) circRNAs can regulate the expression of protein-coding genes through RNA binding proteins; iii) interaction with RNA polymerase can regulate expression of parental genes; iv) some circRNAs can play the same role of directly encoding proteins as mRNA. circRNAs, circular RNAs; miRNAs, microRNAs.

and prognosis. Univariate analysis, further multivariate analysis and the Cox proportional hazard model are also used to assess the prognostic role of circRNAs. circ_100269, circ_0001017 and circ_0061276 have been demonstrated to serve as potential biomarkers for predicting prognosis in GC by these methods $(32,41)$. For instance, Zhang et al (42) indicated that circLARP4 (circ_101057) was closely associated with the prognosis of patients with GC at the early stage rather than at the late stage of the disease. Patients at the early stage of the disease with a high expression of circLARP4 had a better overall survival (OS) and a better response to adjuvant chemotherapy with oxaliplatin and 5 -fluorouracil. The result revealed that circRNA may have the potential to direct clinical medication to a certain extent. The ability of circRNAs alone to determine the prognosis of GC may not meet clinical needs. Chen et al (43) shared a novel approach for this field in 2017. They simultaneously evaluated the predictive values of circPVT1 and PVT1 expression. The combination yielded more accurate results than those obtained by either of the two alone. Future studies are required however, to further concentrate on panels of combined biomarkers to maintain an ideal balance between efficiency and economy.

Therapeutic role of circRNAs in GC. Considerable progress has been made in the identification of the mechanisms through which circRNAs participate in gastric carcinogenesis. Numerous studies have focused on identifying circRNAs that may play potential roles in the treatment of GC (Table I). Multiple circRNAs were selected, and the majority of these were demonstrated to be involved in GC by acting as miRNA sponges. Binding to target miRNAs can downregulate miRNA expression and subsequently affect the functions of downstream molecules. A number of circRNAs have been reported to be upregulated in GC, such as circPVT1, circ_0047905, circ_0138960, circ_7690-15, circHIPK3 (circ_0000284), circ_0023642 and circ_001569. They may participate in cancer proliferation, migration or invasion. Their downregulation can inhibit malignant behaviors (43-47). However, other circRNAs, such as circLARP4 and circ_100269 have been demonstrated to be expressed at lower levels in GC cancer tissues. They have both been demonstrated to be involved in cancer growth, and may function as suppressors of GC through sponging miR-424-5p and miR-630. The upregulation of these two circRNAs significantly reverses carcinogenesis and proliferation $(41,42)$.

The aforementioned circRNAs naturally exist in cancer or normal cells. Their regulation can interrupt or reverse the development of tumors. However, previous studies on GC have focused on basic research, which is far from clinical translation due to complex mechanisms in vivo. Liu et al (54) provided a novel approach of the clinical translation of circRNAs. Since 
Table I. Summary of circRNA mechanisms in GC.

\begin{tabular}{|c|c|c|c|c|}
\hline circRNA & Expression & Pathway & Effects & (Refs.) \\
\hline circ_0001368 & Down & circ_0001368/miR-6506e5p/FOXO3 & $\begin{array}{l}\text { Knockdown of hsa_circ_0001368 } \\
\text { promoted proliferation and invasion } \\
\text { in vitro and accelerated growth in vivo. }\end{array}$ & $(48)$ \\
\hline circNRIP1 & Up & circNRIP1/miR-149-5p/AKT1 & $\begin{array}{l}\text { Knockdown of circNRIP1 inhibited } \\
\text { proliferation, migration, invasion whereas it } \\
\text { could promote EMT and metastasis in vivo. }\end{array}$ & (49) \\
\hline circPSMC3 & Down & circPSMC3/miR-296-5p/PTEN & $\begin{array}{l}\text { Overexpression of circPSMC3 inhibited } \\
\text { cell proliferation, invasion in vitro and } \\
\text { growth, metastasis in vivo. }\end{array}$ & $(50)$ \\
\hline circ_0023642 & Up & UK & $\begin{array}{l}\text { Knockdown of circ_0023642 inhibited } \\
\text { migration, invasion and EMT process. }\end{array}$ & $(47)$ \\
\hline circ_0027599 & Down & circ_0027599/miR-101-3p.1/PHDLA1 & $\begin{array}{l}\text { Overexpression of circ_0027599 } \\
\text { inhibited cell proliferation and metastasis. }\end{array}$ & $(51)$ \\
\hline circPVT1 & Up & circPVT1/miR-125 family & UK & $(43)$ \\
\hline $\operatorname{circAGO} 2$ & Up & circAGO2/HuR/AGO2-miRNA complexes & $\begin{array}{l}\text { CircAGO2 promotes thegrowth, } \\
\text { invasion, and metastasis of cancer cells } \\
\text { in vitro and in vivo. }\end{array}$ & $(52)$ \\
\hline circFAT1 & Down & $\begin{array}{l}\operatorname{circFAT} 1 / \mathrm{miR}-548 \mathrm{~g} / \mathrm{RUNX} 1 \text { and } \\
\text { circFAT1/YBX1 }\end{array}$ & $\begin{array}{l}\text { Overexpression of circFAT } 1 \text { inhibited } \\
\text { proliferation, migration and invasion }\end{array}$ & $(53)$ \\
\hline synthetic & - & scRNA21/miR-21/DAXX & ScRNA21 inhibited & $(54)$ \\
\hline scRNA21 & & & proliferation and induced apoptosis. & \\
\hline circPDSS1 & Up & circPDSS1/miR-186-5p/NEK2 & $\begin{array}{l}\text { CircPDSS1 promoted GC cell cycle, } \\
\text { proliferation and inhibited apoptosis. }\end{array}$ & $(55)$ \\
\hline circPVRL3 & Down & circPVRL3/9 miRNAs & $\begin{array}{l}\text { Knockdown of circPVRL } 3 \text { promoted the } \\
\text { proliferation and migration. }\end{array}$ & $(56)$ \\
\hline $\begin{array}{l}\text { circ-sFMBT2 } \\
\text { circ-SFMBT2 }\end{array}$ & Up & circ-sFMBT2/miR-182-5p/CReB1 & $\begin{array}{l}\text { Knockdown of inhibited the cell } \\
\text { proliferation. }\end{array}$ & $(57)$ \\
\hline circ_0001649 & Down & Unknown & $\begin{array}{l}\text { Knockdown of circ_0001649 } \\
\text { promoted proliferation, migration, } \\
\text { invasion and attenuated apoptosis. }\end{array}$ & $(58)$ \\
\hline circLARP4 & Down & circLARP4/miR-424/LATS1 & $\begin{array}{l}\text { Knockdown of circLARP4 } \\
\text { promoted proliferation and invasion. }\end{array}$ & $(42)$ \\
\hline circ_100269 & Down & circ_100269/miR-630 & $\begin{array}{l}\text { Overexpression of circRNA_100269 } \\
\text { inhibited cell proliferation. }\end{array}$ & $(41)$ \\
\hline ciRS-133 & Up & ciRS-133/miR-133/PRDM16 & $\begin{array}{l}\text { Knockdown of ciRS-133 inhibited cancer } \\
\text { cachexia, decreasing oxygen } \\
\text { consumption and heat production in vivo. }\end{array}$ & (59) \\
\hline circDONSON & Up & Recruitment of NURF & $\begin{array}{l}\text { Silencing of circ-complex to SOX } 4 \\
\text { promoter significantly suppressed the }\end{array}$ & $(60)$ \\
\hline DONSON & & & $\begin{array}{l}\text { proliferation, migration and invasion while } \\
\text { promoting apoptosis. }\end{array}$ & \\
\hline circDLST & Up & miR-502-5p/NRAS & $\begin{array}{l}\text { Knockdown of circDLST inhibited } \\
\text { proliferation, invasion and metastasis. }\end{array}$ & $(61)$ \\
\hline circNHSL1 & Up & miR-13063p/SIX1/vimentin & $\begin{array}{l}\text { Upregulation of circNHSL1 promoted cell } \\
\text { proliferation, migration, invasion. }\end{array}$ & $(62)$ \\
\hline circCACTIN & Up & miR-331-3p/TGFBR1 & $\begin{array}{l}\text { Knockdown of circCACTIN inhibited GC } \\
\text { cells proliferation, migration, } \\
\text { invasion and EMT. }\end{array}$ & (63) \\
\hline circOSBPL10 & Up & miR-136-5p/WNT2 & $\begin{array}{l}\text { circOSBPL10 significantly inhibited cell } \\
\text { growth, migration, and invasion in multiple } \\
\text { experiments. }\end{array}$ & (64) \\
\hline
\end{tabular}


miRNA sponges rely on the antisense sequences, synthetic molecules with these sequences are likely to exhibit similar effects on miRNA inhibition. The researcher can decide the circRNA levels and quantity of binding sites in each circRNA. Controllable modulation ability should provide an optimal balance between efficiency and safety. Liu et al designed a synthetic circRNA functioning as a miR-21 sponge. The administration of this circRNA led to the inhibition of proliferation and induction of apoptosis (54). Downstream proteomic screening revealed that proteins which should have been downregulated by miR-21 were effectively restored (54). Moreover, the reduction of the cancer burden may not be the sole direction of research. The inhibition of ciRS-133 has been shown to alleviate $\mathrm{GC}$-associated cachexia by repressing miR-133 (59). The elucidation of the mechanisms responsible for complications associated with GC is also expected to be meaningful, helping to prolong the lifetime and comfort of patients with late-stage GC. In addition to miRNA sponges, circRNAs in the nucleus can initiate the expression of transcriptional factors to promote cancer growth (60). Future studies are required to pay greater attention to this field and explore additional approaches with which to improve the prognosis and quality of life of patients.

\section{Long non-coding RNAs (IncRNAs)}

lncRNAs belong to a characterized group of RNAs without the capacity of transcription, which are $>200 \mathrm{nt}$ in length. In the 1990s, lncRNAs were identified without optimal origins and functions (65). IncRNAs were initially regarded as transcriptional noises (66). However, accumulating evidence suggested that lncRNAs may play a crucial role in physiological activities and various diseases (67-69). Compared with their small-length counterparts, miRNAs, the main functional mechanism of which is binding to $3^{\prime}$ untranslated regions and activating the degradation of target mRNAs (70), lncRNAs have richer regulatory methods, including levels of transcription, post-transcription, alternative splicing and translation (71). For instance, IncRNA h5S-OT modulates retrotransposons jump into alternative-splicing by virtue of the Alu element. Alternative splicing produces variants of proteins responsible for distinct physiological or pathological processes $(72,73)$. lncRNA RoR has been reported to interact with c-Myc mRNA and increase its stability, leading to cell proliferation and tumorigenesis (74). IncRNA-protein regulatory mechanisms can be generally summarized by four aspects: i) Signal, lncRNAs reflect on the spatiotemporal expression level of genes via alterations of transcription factors or signaling pathways; ii) decoy, lncRNAs titrate specific proteins in the cell nucleus and perform concrete functions; iii) guide, lncRNAs direct ribonucleoprotein complex to locate on specific regions; and iv) scaffold, the lncRNA scaffold is structural and stabilizes nuclear structures or signaling complexes (75) (Fig. 2).

The association between lncRNAs and GC has been gradually revealed. Numerous lncRNAs have been found to participate in carcinogenesis and progression. Diverse biological functions and wide distribution determines the complexity of lncRNA networks in GC. One lncRNA can regulate multiple cancer behaviors through different pathways $(76,77)$. One cancer behavior can be under the control of several
IncRNAs and their respective downstream molecules $(78,79)$. Additionally, intersectional lncRNA profiles and regulatory mechanisms vary in different cancer types $(80,81)$. Their theoretical links with GC provide substantial biomarkers and targets with potential clinical values. Therefore, lncRNAs are one of the most promising approaches for GC diagnosis and treatment.

Diagnostic role of lncRNAs in GC. The biological characteristics of IncRNAs facilitate the speed of translation into the clinical diagnosis of GC. Optimal diagnostic biomarkers require remarkable stability of molecular structures and expression levels. Given the existing number of studies, lncRNAs are suitable candidates for this purpose. lncRNAs have been found to stably exist in extreme environments, such as gastric juice, urine and hair follicles (82-84). IncRNAs have distinct half-life periods, which range from $<2$ to $>16 \mathrm{~h}(85)$. A long half-life period would lead to the accumulation and would impair the accuracy of the biomarker. On the other hand, an excessively short detectable time exerts more pressure on the limitation of technology to form a reliable clinical diagnosis. In a previous study, the median half-life period of lncRNAs was $\sim 3.5 \mathrm{~h}$ shorter than that of protein-coding RNAs (85). The appropriate half-life period indicates their potential to function as diagnostic biomarkers due to the prompt reactions of lncRNAs consistent with the degrees of primary focus. The characteristics and severity of diseases can be reflected by these reliable indicators.

The majority of studies concerning lncRNA diagnosis have focused on the detection of cancerous tissues. Alterations in lncRNA expression are significantly associated with numerous clinicopathological features. For instance, Sun et al (86) found that lncRNA AC096655.1-002 expression was associated with TNM stage, differentiation, lymph node metastasis and depth of invasion. 1ncRNA ABHD11-AS1 has also been proven to be associated with differentiation, Lauren histological classification and carbohydrate antigen 19-9 (CA19-9) (87). Testing the expression levels of some lncRNAs may provide a reference for the evaluation of disease severities and the selection of treatment regimens. However, the association between lncRNAs and clinicopathological features is not stable. Baratieh et al (88) analyzed data from patients with GC in The Cancer Genome Atlas (TCGA) database. Their results revealed limited features associated with FAM83H-AS1 expression; however, FAM83H-AS1 mean and median gene expression data in the TCGA cohort exhibited a significant association with M-classification, tumor stage, grade and different Lauren's classes. Thus, further investigations into more reliable associations of lncRNAs with clinical characteristics are required using larger sample numbers and standardizing experimental procedures.

Non-invasive and pain-free detection methods of lncRNAs are also pursued, such as in the case of circRNAs. lncRNA performance in GC diagnosis is commonly better than that of classical biomarkers, as highlighted from current methods, such as CEA and CA19-9 (89). A meta-analysis (90) indicated that the clinical values of lncRNAs are limited to screening tools rather than diagnosis with high accuracy. This conclusion may not be convincing enough, partly due to the inclusion of relatively old studies and the ignorance of the respective 


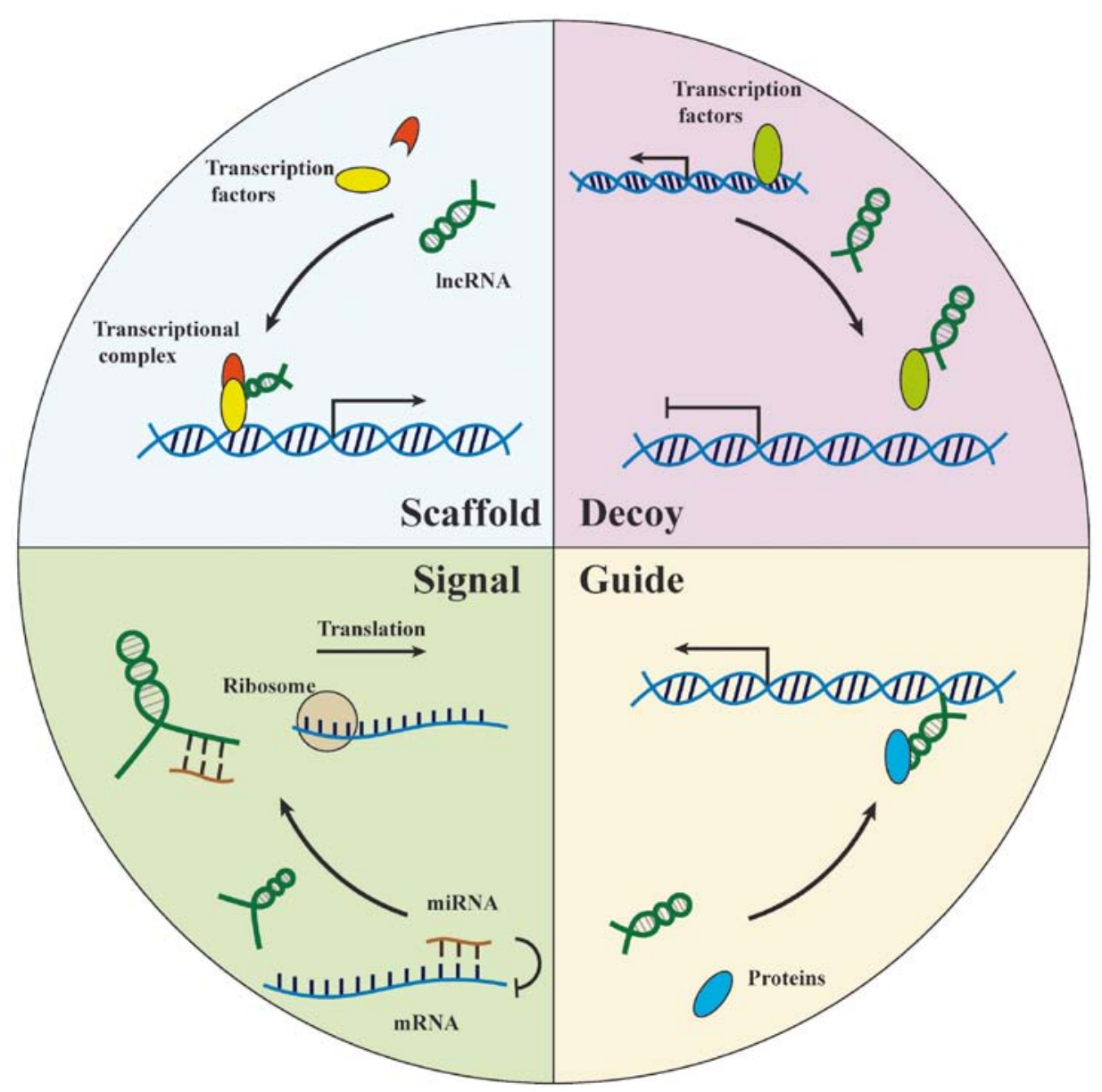

Figure 2. Biological functions of lncRNAs. The biological functions of lncRNAs can be classified into four aspects: i) Scaffold, lncRNA scaffold is structural and stabilizes nuclear structures or signaling complexes; b) decoy, IncRNAs titrate specific proteins in the cell nucleus and perform concrete functions; c) signal, lncRNAs can participate in the regulation of signaling pathways and reflect on spatiotemporal expression level of relative genes; iv) guide, lncRNAs direct ribonucleoprotein complex to locate on specific regions. IncRNAs, long non-coding RNAs.

discussions of each lncRNA. Some lncRNAs have exhibited great potential for clinical translation. IncRNA H19 and HOTAIR were demonstrated to be effective biomarkers with high AUC. Their combination with CEA significantly enhanced their diagnostic capacity (91-93). Furthermore, a multi-lncRNA diagnostic panel in plasma is a feasible approach to compensate for the comparably low sensitivity of a single lncRNA. Dong et al (89) created a panel with three plasma lncRNAs (CUDR, LSINCT-5 and PTENP1) in 2015, which was sensitive and specific to the discrimination of healthy controls from patients with GC, patients with peptic ulcers from patients with GC, and patients with stage I and II-IV disease from healthy controls. Zhang et al (94) employed the genome-wide profiling identifies TINCR, CCAT2, AOC4P, BANCR and LINC00857 in plasma. The diagnostic panel was estimated to be an excellent method for the discrimination of patients with GC from both precancerous individuals and gastrointestinal stromal tumors. Another advantage of this research is that these data were translated into Fagan's nomogram, a tool used to calculate the probability that an individual has GC based on this panel. A convenient evaluation method is a developing direction of GC diagnosis. In addition, $\mathrm{Li}$ et al (95) found that the levels of LINC00152 in plasma and exosomes were consistent, which suggested that lncRNAs detected in exosomes may also have optimal clinical values as plasma biomarkers.
Some studies have focused on lncRNAs in gastric juice (Table II). These stomach-specific, single-source biomarkers can be easily obtained with non-invasive methods, and multiple lncRNA targets have been selected. IncRNA ABHD11-AS1 and UCA1 were found in gastric juice with an AUC of 0.653 and 0.721 , respectively. These data do not seem satisfactory. However, the specificities of ABHD11-AS1 and UCA1 were 0.934 and 0.803 , respectively $(84,96)$. lncRNAs can serve as outstanding indicators of excluded diagnosis. As sensitive indicators at fluctuating levels are influenced by numerous factors; thus, accurate detection needs another reliable biomarker for revision. Shao et al (97) found that GAPDH was a satisfactory reference for lncRNAs in plasma and gastric juice. Their combination with GAPDH may elevate the clinical confidence level of diagnostic biomarkers.

Current treatment methods cannot reach curative goals for patients at advanced stages of the disease. A basic method with which to resolve GC-associated mortality and the poor prognosis of affected patient is to search for efficient diagnostic biomarkers for the early stages of the disease. H. pylori is an important carcinogenic factor, estimated to be prevalent in developing countries $(102,103)$. NR_026827 has been demonstrated to be downregulated in gastric epithelial cells infected with $H$. pylori (104). Despite the wide application of $\mathrm{C}^{13}$ or $\mathrm{C}^{14}$ examinations, NR_026827 
Table II. Summary of lncRNAs in gastric juice.

\begin{tabular}{|c|c|c|c|c|c|c|}
\hline lncRNA & Locus & AUC of tissues & AUC of plasma & AUC of gastric juice & Conclusion & (Refs.) \\
\hline UCA1 & 19 p13.12 & 0.721 & 0.838 & UK & $\begin{array}{l}\text { UCA1 in gastric juice is } \\
\text { significantly higher than } \\
\text { normal individuals. }\end{array}$ & (96) \\
\hline ABHD11-AS1 & $7 q 11.23$ & UK & UK & 0.653 & $\begin{array}{l}\text { Combinative use of } \\
\text { ABHD11-AS1 and CEA } \\
\text { promotes the positive rates of } \\
\text { advanced GC. }\end{array}$ & (84) \\
\hline RMRP & $9 p 13.3$ & UK & 0.639 & 0.699 & $\begin{array}{l}\text { RMRP in gastric juice has } \\
\text { higher diagnostic value, } \\
\text { particuarly for specificity } \\
\text { compared with those in plasma. }\end{array}$ & (98) \\
\hline AA174084 & $\operatorname{chr} 13$ & 0.676 & UK & 0.848 & $\begin{array}{l}\text { AA174084 in gastric juice } \\
\text { levels has great potential as a } \\
\text { screening biomarker of early GC. }\end{array}$ & (97) \\
\hline LINC00152 & $2 \mathrm{p} 11.2$ & 0.645 & UK & UK & $\begin{array}{l}\text { LINC00152 in gastric juice } \\
\text { levels from patients with } \\
\text { gastric cancer were } \\
\text { significantly higher } \\
\text { than those from } \\
\text { normal subjects. }\end{array}$ & (99) \\
\hline LINC00982 & $1 \mathrm{p} 36.32$ & 0.742 & UK & UK & $\begin{array}{l}\text { LINC00982 in gastric juice } \\
\text { levels from patients with } \\
\text { gastric cancer were } \\
\text { significantly higher than } \\
\text { those from normal subjects. }\end{array}$ & $(100)$ \\
\hline H19 & $11 \mathrm{p} 15.5$ & 0.697 & 0.838 & UK & $\begin{array}{l}\text { H19 levels in gastric } \\
\text { juice from patients with } \\
\text { GC were significantly higher } \\
\text { than those from normal subjects. }\end{array}$ & $(93,101)$ \\
\hline
\end{tabular}

GC, gastric cancer; lncRNA, long non-coding RNA; UK, unknown.

may be a predictive role of GC risks. H19 in plasma enabled the discrimination of early-stage GC from controls with an AUC of 0.877 (93). Lu et al (105) also developed a panel of five lncRNAs in tumor tissues with high values of early diagnosis, which helps to identify indistinguishable focus in endoscopy. The single nucleotide polymorphism (SNP) rs4759314, which contributes to a genotype-specific effect on the expression of the host gene HOTAIR, has been shown to be closely associated with the risk of developing GC in Chinese populations (106).

Prognostic role of lncRNAs in GC. The number of lncRNAs for the prediction of prognosis remains smaller than that for GC diagnosis. A substantial number of lncRNAs have been screened out, which have remarkable predicting performance, theoretically. The majority of previous studies suggest the potential values of tissue lncRNAs in evaluating the survival of patients with GC. Liu and Shangguan (107) employed the Kaplan-Meier curve to prove that high level of lncRNA
CARLo-5 was associated with overall survival (OS) and recurrence-free survival (RFS). Further univariate and multivariate analyses indicated that CARLo-5 could serve as an independent predictor of OS and RFS. Feng et al (108) reported that patients with a high expression of 1ncRNA AFAP1-AS1 had a significantly poorer OS. Some other biomarkers for the prediction of prognosis have been identified in recent years, such as CASC15, UPF1, ZEB1-AS1 and PANDAR (109-112). They were all found to be independent prognostic factors of survival time.

The degree of metastasis is an important factor for patient prognosis, and there is a close association between lncRNAs and GC metastasis. Xia et al (113) found that MALAT1 both in tissue and plasma could serve as a prognostic biomarker of distant metastasis. CARLo- 5 has also been reported to be associated with lymph node involvement and distant metastasis (107).

Nevertheless, the selected predictors are considerable, while the pace of clinical translation has stagnated for a long 
time. None of these lncRNAs can reach the criterion of wide application. A previous study even demonstrated that a combination of 24 lncRNAs had the clinical value of predicting prognosis (114). Superfluous lncRNAs in a panel may decrease the prognostic values and increase the economic burden of patients. Overall, the value of lncRNAs is not regarded as a preferable indicator for the prediction of prognosis based on current studies.

Therapeutic role of lncRNAs in GC. The identification of the elusive mechanisms of carcinogenesis and progression remains at a preliminary stage. Both explored and unexplored pathological processes contain multiple molecules with clinical values. Unlike diagnostic and prognostic biomarkers, a therapeutic candidate requires the marked involvement of important mechanisms; thus, there is a great difficulty. Numerous studies have paid attention to lncRNAs in the view of the established regulatory network of GC. Large quantities of targets have been successfully selected to act as potential targets of clinical treatment. For instance, Chen et al (115) measured the expression of lncRNA-ATB in a pathological specimen in GC cell lines by RT-qPCR. IncRNA-ATB was found to be significantly upregulated in cancer tissues and cell lines. Its knockdown led to the alteration of clinicopathological features, including proliferation, invasion and migration (115).

Long intergenic non-coding RNAs (lincRNAs) are one of the four defined categories of lncRNAs (116). lincRNAs and lncRNAs share similar features. However, the difference between the two types of molecules should be emphasized, owing to frequent errors made by numerous studies, including gene expression analyses, evolutionary conservation patterns and targeted gene disruptions that did not alter adjacent protein-coding genes or genic RNAs (117). Previous studies have suggested that lincRNAs may be potential targets of treatment. HOTAIR is recognized as a key lincRNA in GC, which can modulate cancer development and fate determination through multiple molecules and pathways. HOTAIR, as a type of non-coding RNA sponge, can competitively inhibit several miRNAs and affect downstream functioning molecules, such as miR-217, miR-152, miR-454-3p and miR-17-5p (118-121). The interaction of HOTAIR with crucial proteins also plays an indispensable role in various biological functions of GC. Runx3 endows gastric cells with the capacity of excessive proliferation and invasion (122). The combination of HOTAIR and Mex3b, a type of E3 ligase possessing RNA binding domains, can attenuate the degradation of Runx3, thus regulating cancer migration and invasion (123). Zeng et al (124) found that LINC00675 could enhance the phosphorylation of vimentin on Ser8 and the p53 signaling pathway. The downregulation of LINC00675 facilitated cancer proliferation, migration and invasion in vitro and in vivo (124). Previous studies have validated that LINC00052, Linc00152, Linc00483 and H19 are attributable to the genesis and development of GC (125-128). The intervention of their expression may lead to the reversion of cancer progression and an improvement in patient prognosis.

Drug resistance can limit the efficacy and effectiveness of GC treatments. The prognosis and quality of life of numerous patients deteriorate at the late stages of the disease due to the failure of existing chemotherapeutics or targeted medicine (129). Previous studies have indicated that lncRNAs may be capable of preventing and reversing drug resistance. A high expression of GHET1 and ANRIL was detected in GC tissues. Further experiments demonstrated that these two lncRNAs were associated with multi-drug resistance (MDR)-related genes. The attenuation of these sensitized the reactions of GC cells $(130,131)$. CASC2 overexpression has also been shown to overcome cisplatin resistance by binding to miR-19a, whereas MALAT1 potentiates cisplatin resistance through sponging miR-30b $(132,133)$.

An increase in the apoptotic protein, cleaved caspase-3, has been shown to restore the sensitivity to multiple drugs, including doxorubicin, cisplatin and 5-fluorouracil $(134,135)$. Autophagy is a complex and highly regulated process that delivers cellular material to lysosomes for degrading, recycling, and generating molecules that fuel cellular metabolism (136). Recent research has revealed that there is a close association between autophagy and MDR (137). Two studies separately explained the mechanisms of MALAT1-induced autophagy concerning the formation of GC resistance. MALAT1 served as a miRNA sponge to target miR-23-3p and miR-30b, and related proteins downstream of autophagy functioned subsequently $(132,138)$. The inhibition of MALAT1 was considered as a promising approach to alleviating MDR at late stages.

The regulatory mechanisms of lncRNAs re not simply considered as a 'one-to-many' mode. Previous evidence suggests that lncRNAs share the same regulated targets. These common targets cannot only help delineate sophisticated networks of non-coding RNAs and GC, but also serve as intervention sites with great values. YB-1 is a multifunctional protein that regulates apoptosis, cell proliferation, differentiation and stress response (139). IncRNAs GAS5 and HOXC-AS3 can directly bind to YBX1 proteins, promoting the conversion of YBX1 configuration. The inhibition of these two lncRNAs in GC cells has been shown to abolish G1 phase cell cycle arrest, and the cell proliferative capacity has been shown to be considerably enhanced $(140,141)$. Moreover, EZH2, which is associated with genetic abnormalities, has been found to participate in the regulation of epigenetics and transcription. HOTAIR, MALAT1, UCA1 and LINC00673 can interact with EZH2 and suppress downstream E-cadherin, PCDH10, AKT and KLF4, respectively (142-145). The inhibition of the intersection of the mechanism means partially refraining functions of upstream lncRNAs. Therapeutic efficacy may be enlarged manifold.

Despite progress being made in determining the role of lncRNAs in the treatment of GC, none of these lncRNAs have reached the standard of clinical translation to date. A few key lncRNAs, including HOTAIR, UCA1 and MALAT1, have been reported to regulate various downstream molecules and suppress tumors in vitro and in vivo. Relevant agents for clinical use were kept at a slow pace due to the distinction between human physiological processes and simulation environment of cells and animals. Furthermore, the existing mechanisms were scattered and unable to constitute an integral network. The inability to recognize the overall perspective of may set obstacles for finding regimens of curing GC thoroughly. Additional in-depth investigations are warranted to mine more effective therapeutic targets. 
Table III. Summary of lncRNAs and circRNAs in exosomes in GC.

\begin{tabular}{|c|c|c|c|c|c|}
\hline RNA & Diagnostic potentials & Prognostic potentials & Therapeutic potentials & Conclusion & (Refs.) \\
\hline $\begin{array}{l}\text { lncRNA } \\
\text { ZAFS1 }\end{array}$ & + & + & + & $\begin{array}{l}\text { LncRNA ZASF1 can } \\
\text { enhance cell proliferation } \\
\text { and migration, which also } \\
\text { serves as a potential } \\
\text { diagnostic and prognostic } \\
\text { biomarker. }\end{array}$ & (149) \\
\hline ciRS-133 & - & - & + & $\begin{array}{l}\text { Intervention of ciRS- } 133 \text { can } \\
\text { alleviate cachexia caused by GC. }\end{array}$ & (59) \\
\hline $\begin{array}{l}\text { lncRNA } \\
\text { UEGC1 }\end{array}$ & + & - & - & $\begin{array}{l}\text { LncRNA UEGC1 may serve } \\
\text { as a reliable diagnostic } \\
\text { biomarker of early GC. }\end{array}$ & $(150)$ \\
\hline LINC00152 & + & - & - & $\begin{array}{l}\text { LINC00152 can be a } \\
\text { potential biomarker of GC } \\
\text { diagnosis with high } \\
\text { specificity but low sensitivity. }\end{array}$ & (95) \\
\hline $\begin{array}{l}\text { lncRNA } \\
\text { HOTTIP }\end{array}$ & + & + & - & $\begin{array}{l}\text { LncRNA HOTTIP was } \\
\text { reported to act as an } \\
\text { excellent diagnostic and } \\
\text { prognostic biomarker. }\end{array}$ & $(151)$ \\
\hline $\begin{array}{l}\text { circ- } \\
\text { KIAA } 1244\end{array}$ & + & - & - & $\begin{array}{l}\text { Circ-KIAA } 1244 \text { can serve a } \\
\text { novel circulating biomarker } \\
\text { for detection of GC. }\end{array}$ & $(152)$ \\
\hline circ_0065149 & + & + & - & $\begin{array}{l}\text { Circ_0065149 in exosomes is an } \\
\text { indicator for early GC } \\
\text { screening and prognosis prediction. }\end{array}$ & (153) \\
\hline
\end{tabular}

GC, gastric cancer; lncRNA, long non-coding RNA; circRNA, circular RNA; +, reported; -, unknown.

\section{IncRNAs and circRNAs in exosomes}

Exosomes are nm-sized vesicles in the extracellular fluid, which span 40-150 $\mathrm{nm}$ and contain numerous functional molecules such as proteins, miRNAs, lncRNAs and circRNAs. The exploration of exosome-relevant surface markers and transmission electron microscope contribute to the development of detection and further research. The processes of formation, content selection, loading, trafficking and release of exosomes are strictly under physical control (146-148).

Disorders of exosomes in GC have been revealed in recent years (Table III). Exosomes and inclusion compounds may play an important role in the deterioration and metastasis of GC. Pan et al (149) found that lncRNA ZFAS1 in exosomes enhanced GC cell proliferation and migration, while ciRS-133 in exosomes has been shown to participate in lipid metabolism and to be associated with cancer cachexia (59).

On the other hand, alteration in the levels and modified states of lncRNAs and circRNAs have potential for use in the diagnosis and prognosis of GC. Exosomes encapsulate biomarkers and protect them from RNase degradation, which endow them with extraordinary stability and capability of representativeness. For example, Lin et al found that lncUEGC1 was early GC-specific, and could discriminate patients with early GC from healthy individuals and those with premalignant chronic atrophic gastritis (150). Moreover, LINC00152, lncRNA HOTTIP, circ-KIAA1244 and circ_0065149 were identified as biomarkers for GC diagnosis and prognosis $(95,151-153)$.

\section{Comparison of achievements regarding circRNAs and IncRNAs}

circRNAs and lncRNAs both belong to the family of non-coding RNAs. Similar constructions determine consistent characteristics: i) Relative incapacity of expressing proteins; ii) some highly conserved sequences; iii) stable existence in extreme environments for a relatively long period of time; iv) wide varieties and distribution; v) diversity and complexity of the involved regulatory mechanisms; and vi) association with multiple diseases. The isoforms derived from the same genes have been demonstrated to play important roles in cancer. For instance, lncRNA PVT1 and circPVT1 both play oncogenic roles in GC progression, and have great diagnostic and therapeutic potential $(43,154)$. The biological functions also overlap. circRNAs and lncRNAs can bind to miRNAs through complementation, which serves as a negative regulatory method for 
target miRNAs. During the past decade, numerous studies concerning miRNAs have been published $(20,21,44,52)$. The network of miRNAs in tumorigenesis has begun to take shape. The association of miRNAs with lncRNAs and circRNAs suggests a vast number of uncovered regulatory pathways. The classical view indicates that circRNAs and lncRNAs lack the capacity of coding proteins. However, recent evidence supports coding competence for these (155), which universally overturns traditional impression. Additionally, although limited studies have been published regarding the crosstalk of circRNAs and lncRNAs, the shared features indicated an abundance of underlying interactions in carcinogenesis and development. Further basic and translational studies are required on this topic.

Researchers strive to identify a novel method of clinical translation. As aforementioned, circRNAs and lncRNAs have great potential for use in the diagnosis and treatment of GC. Extensive focus has been placed on lncRNAs over the past decade, with multiple studies suggesting effective clinical performance for GC. Although circRNAs have been discovered for a long time, they have only increased in popularity in recent years. However, unique translational methods of circRNAs provide a new direction for clinical use and research. Both ncRNAs have their own strengths and shortcomings.

According to previous studies (86-88,91-93,106-114), the diagnostic and prognostic values of lncRNAs are ideal. Initially, researchers tested single lncRNA values in GC; however, the result could not reach clinical standards. Next, panels of lncRNAs or lncRNA combined with other types of biomarkers were developed, which exhibited good sensitivity and specificity, particularly compared with those of classical cancer biomarkers. The Fagan's nomogram created by Zhang et al (94) accelerated the pace of lncRNA diagnosis. Nevertheless, practical usage requires not only theoretical effects, but also a cost-benefit balance. If a large number of lncRNAs is involved, this can hinder making definite conclusions and can increase medical costs, thus adding pressure for both doctors and patients. In terms of circRNAs, previous studies have focused on single molecules or on their combination with other biomarkers $(30,32-42)$. The results were relatively satisfactory. However, similar to lncRNAs, the future role of circRNAs in GC diagnosis and prognosis requires more systematically designed studies and long-term clinical trials. Another developmental direction is to combine panels with several types of ncRNAs. The RNAs with optimal clinical performance and robust endurance in extreme environments should be collected and compensate for the shortcomings of single biomarkers. The exploration of associated biomarkers is necessary in order to promote their clinical application.

The location association of IncRNAs and circRNAs is important for the exploration of their potential clinical translation. Distinct location endows these molecules with different biological functions. IncRNAs were estimated to be mostly located in the nucleus, while circRNAs are mostly located in the cytoplasm, acting as the miRNA sponges to regulate downstream signaling pathways. This location association determines their potential for use in clinical research or practice. Researchers should not only verify their experimental capability of interfering GC progression, but also ascertain the natural location of these molecules in cancer cells.
A novel therapeutic method for GC relies on the elucidation of the mechanisms responsible for the development of GC. Previous studies have screened out numerous circRNAs and IncRNAs with therapeutic potential (41-43,47-64,115,118-121,123-128,132,133,138,140-145), mainly by small interference in vitro and by inhibition of tumor burden in vivo. Various new signaling pathways were identified, which were connected with established cancer promoters or suppressors. The reported efficacy of regulating circRNAs and lncRNAs was demonstrated to be effective. It is worth mentioning that the application of synthetic circRNAs offers a brand-new perspective for researchers, which is considered as a more direct and controllable method for GC treatment. The limitations of these studies are evident. Basic studies cannot replace clinical trials. Unknown efficacy, administration method and dosage of human agents hinder the further use of these RNAs. The therapeutic regimens should also refer to the cost-benefit principle. No studies available to date have reported the side-effects associated with the interference, at least to the best of our knowledge. In short, detailed information on therapeutic applications requires more in-depth investigations.

\section{Prospects}

The following are some suggestions for the development of circRNAs and lncRNAs. Firstly, sample sizes should be enlarged. The majority of studies collected tissue and plasma samples from <200 GC patients with GC. The limited number of sources definitely increases the contingency of false results. Despite the lack of evidence, circRNA and lncRNA profiles may vary in different groups of age, ethnicity, and living conditions. Therefore, additional large-scale, multi-center studies conducted under strict supervision are required, which will draw more convincible and compelling conclusions. More reliable information is also required for individual diagnosis.

Secondly, clinical trials concerning optimal biomarkers should be implemented as early as possible. Despite findings of therapeutic targets at the preliminary stages, the diagnostic and prognostic biomarkers have been demonstrated to be more convenient and efficient than compared to classical use. Plasma detection is a promising future due to non-invasive examination, a high acceptance by patients and better sensitivity. With the development of detection technologies, circRNAs and lncRNAs can be measured in gastric juice, which has exhibited great efficacy in the diagnosis of GC. Their high stability endows these biomarkers with the ability to endure extreme environments. Furthermore, despite the limited number of studies available concerning lncRNAs and circRNAs in exosomes of GC, exosomes can serve as shields to protect non-coding RNAs from RNases and extreme environments. The potential diagnostic values of lncRNAs and circRNAs in exosomes need to be more deeply investigated. Exosomes may also be effective transporters of RNA interference drugs. Additional detection media for GC diagnosis and prognosis, such as feces, warrant further exploration in the future. These gastrointestinal-specific, alteration-immediate biomarkers will be more promising for future applications. 
Thirdly, the distinction of cancer locations in GC should be recognized. Previous research has suggested that carcinogenesis in different sites of GC, such as the cardia and antral stomach, involves different mechanisms (156). However, to the best of our knowledge, to date, there are no studies available differentiating the location discrepancy. Studies have explored circRNA and lncRNA profiles, and the regulatory pathways in the whole stomach, which may be an important factor leading to partially contradictory results, attenuating the development of clinical translation, and promoting the unbalance of clinical accuracy and practicability.

Fourthly, the disturbance of non-cancer factors should be emphasized. circRNAs and lncRNAs exist in both normal and pathological tissues, and are secreted into the extracellular environment. Previous studies showed that the expression of these two kinds of RNAs can be influenced by numerous non-cancer factors, including inflammation, neurodegenerative diseases, drugs and circadian rhythms (157-161). The fluctuation of circRNA and lncRNA levels leads to inaccurate results. It is advisable to remove background disturbances by mathematical modulation or molecular biology techniques. On the other hand, diagnostic and prognostic translation of circRNA and lncRNA levels requires normative criterion of sampling time, methods and criteria of patients' inclusion and exclusion.

Fifthly, the specificity of circRNAs and lncRNAs can be poor, which decreases down the accuracy and safety of non-coding RNA interference in patients. This may be an important reason for the slow pace of relevant therapeutic drugs. An efficient approach is to administer drugs in situ, since this can reduce the effects on non-targets and optimize the sufficient dose of drugs for tumor focus. The efficacy and accompanying side-effects can be easily observed in animal models. However, administration in situ definitely would lead to more difficulties in clinical practice and patient compliance. Biomaterial serves as a robust star for modern biomedicine. A large number of novel transporter systems have been established, and have been demonstrated to be effective for maximizing the specificity and minimizing side effects of interference drugs, such as nanoparticles and nanotube sponges. More efficient and reliable mediators should be constructed to improve the specificity and reduce the side-effects of IncRNA and circRNA treatment.

\section{Conclusion}

The advantages and disadvantages of these two types of RNA have been compared in the present review based on their similar biological features and research achievements. Accumulating evidence has revealed their essential role in the diagnosis, prognosis and treatment of GC. Certain circRNAs and lncRNAs have been reported to exhibit optimal effects and act as convenient detection methods. Panels of combined biomarkers serve as a novel trend in early diagnosis and prognostic prediction. Furthermore, the identification of the mechanisms responsible for GC can promote the development of GC therapeutic targets. Previous studies have identified numerous circRNA and lncRNA molecules $(28-31,82,85,94,114)$, as well as relevant signaling pathways. The interference of target expression significantly affects GC cell behavior and tumor burden.
However, there are still several limitations concerning circRNAs and lncRNAs. The number of previous studies on these molecules is relatively small, and numerous unknown molecules require further exploration. Publication bias may partly cover the potential targets. The small number of collected samples and the different GC locations impair the reliability of the results. A number of translational questions remain to be answered, such as: i) the clinical position compared with that of classical biomarkers and therapeutic regimens; ii) the development of strategies with which to combine biomarkers to reach the cost-benefit balance; and iii) the development of strategies with which to administer circRNA and lncRNA disruptors into the human body with minimal side-effects and optimal efficacy. It is too early to assert definite values in clinical application.

In conclusion, the present review summarized the current achievements of circRNAs and lncRNAs in GC. Numerous biomarkers and targets were selected with theoretically optimal performance. However, several issues remain to be resolved. The translational procedures will encounter setbacks and difficulties. Nevertheless, it is expected that circRNAs and lncRNAs will play crucial roles in the diagnosis and treatment of $\mathrm{GC}$ in the future.

\section{Acknowledgements}

Not applicable.

\section{Funding}

The present study was supported by grants from the National Natural Science Foundation of China (grant no. 81773135) and Beijing Science and Technology Commission Bio-Medicine and Bio-Science Innovation Research Major Subject (grant no. Z171100000417023).

\section{Availability of data and materials}

Not applicable.

\section{Authors' contributions}

BC and GL were mainly responsible for collecting relevant information and completing this review. WZ and YS were mainly responsible for consulting literature materials and revising the manuscript. BW was responsible for the conception of this review and the assignment of tasks. There was no additional assistance with manuscript preparation. All authors read and approved the final manuscript.

\section{Ethics approval and consent to participate}

Not applicable.

\section{Patient consent for publication}

Not applicable.

\section{Competing interests}

The authors declare that they have no competing interests. 


\section{References}

1. Bray F, Ferlay J, Soerjomataram I, Siegel RL, Torre LA and Jemal A: Global cancer statistics 2018: GLOBOCAN estimates of incidence and mortality worldwide for 36 cancers in 185 countries. CA Cancer J Clin 68: 394-424, 2018.

2. Ilson DH: Advances in the treatment of gastric cancer. Curr Opin Gastroenterol 33: 473-476, 2017.

3. Zurleni T, Gjoni E, Altomare $\mathrm{M}$ and Rausei S: Conversion surgery for gastric cancer patients: A review. World J Gastrointest Oncol 10: 398-409, 2018

4. Pernot S, Voron T, Perkins G, Lagorce-Pages C, Berger A and Taieb J: Signet-ring cell carcinoma of the stomach: Impact on prognosis and specific therapeutic challenge. World J Gastroenterol 21: 11428-11438, 2015.

5. Kolakofsky D: Isolation and characterization of Sendai virus DI-RNAs. Cell 8: 547-555, 1976

6. Hsu MT and Coca-Prados M: Electron microscopic evidence for the circular form of RNA in the cytoplasm of eukaryotic cells. Nature 280: 339-340, 1979

7. Capel B, Swain A, Nicolis S, Hacker A, Walter M, Koopman P, Goodfellow P and Lovell-Badge R: Circular transcripts of the testis-determining gene Sry in adult mouse testis. Cell 73: 1019-1030, 1993

8. Cocquerelle C, Mascrez B, Hetuin D and Bailleul B: Mis-splicing yields circular RNA molecules. FASEB J 7: 155-160, 1993.

9. Kristensen LS, Hansen TB, Veno MT and Kjems J: Circular RNAs in cancer: Opportunities and challenges in the field. Oncogene 37: 555-565, 2018.

10. Yu T, Wang $\mathrm{Y}$, Fan Y, Fang N, Wang T, Xu T and Shu Y: CircRNAs in cancer metabolism: A review. J Hematol Oncol 12: 90, 2019.

11. Memczak S, Jens M, Elefsinioti A, Torti F, Krueger J, Rybak A, Maier L, Mackowiak SD, Gregersen LH, Munschauer M, et al Circular RNAs are a large class of animal RNAs with regulatory potency. Nature 495: 333-338, 2013.

12. Chen LL: The biogenesis and emerging roles of circular RNAs. Nat Rev Mol Cell Biol 17: 205-211, 2016.

13. Jeck WR, Sorrentino JA, Wang K, Slevin MK, Burd CE, Liu J, Marzluff WF and Sharpless NE: Circular RNAs are abundant, conserved, and associated with ALU repeats. RNA 19: 141-157, 2013.

14. Wang PL, Bao Y, Yee MC, Barrett SP, Hogan GJ, Olsen MN, Dinneny JR, Brown PO and Salzman J: Circular RNA is expressed across the eukaryotic tree of life. PLoS One 9: e90859, 2014

15. Han D, Li J, Wang H, Su X, Hou J, Gu Y, Qian C, Lin Y, Liu X Huang M, et al: Circular RNA circMTO1 acts as the sponge of microRNA-9 to suppress hepatocellular carcinoma progression. Hepatology 66: 1151-1164, 2017.

16. Kulcheski FR, Christoff AP and Margis R: Circular RNAs are miRNA sponges and can be used as a new class of biomarker. J Biotechnol 238: 42-51, 2016.

17. Du WW, Zhang C, Yang W, Yong T, Awan FM and Yang BB: Identifying and characterizing circRNA-protein interaction. Theranostics 7: 4183-4191, 2017.

18. Li Z, Huang C, Bao C, Chen L, Lin M, Wang X, Zhong G, Yu B, Hu W, Dai L, et al: Exon-intron circular RNAs regulate transcription in the nucleus. Nat Struct Mol Biol 22: 256-264, 2015.

19. Pan J, Meng X, Jiang N, Jin X, Zhou C, Xu D and Gong Z: Insights into the noncoding RNA-encoded peptides. Protein Pept Lett 25: 720-727, 2018.

20. Jin X, Feng CY, Xiang Z, Chen YP and Li YM: CircRNA expression pattern and circRNA-miRNA-mRNA network in the pathogenesis of nonalcoholic steatohepatitis. Oncotarget 7: 66455-66467, 2016

21. Piwecka M, Glazar P, Hernandez-Miranda LR, Memczak S, Wolf SA, Rybak-Wolf A, Filipchyk A, Klironomos F, Cerda Jara CA, Fenske P, et al: Loss of a mammalian circular RNA locus causes miRNA deregulation and affects brain function. Science 357: eaam8526, 2017.

22. Zhao M, Gao F, Zhang D, Wang S, Zhang Y, Wang R and Zhao J: Altered expression of circular RNAs in Moyamoya disease. J Neurol Sci 381: 25-31, 2017.

23. Hsiao KY, Lin YC, Gupta SK, Chang N, Yen L, Sun HS and Tsai SJ: Noncoding effects of circular RNA CCDC66 promote colon cancer growth and metastasis. Cancer Res 77: 2339-2350, 2017.
24. Tang YY, Zhao P, Zou TN, Duan JJ, Zhi R, Yang SY, Yang DC and Wang XL: Circular RNA hsa_circ_0001982 promotes breast cancer cell carcinogenesis through decreasing miR-143. DNA Cell Biol 36: 901-908, 2017.

25. Nair AA, Niu N, Tang X, Thompson KJ, Wang L, Kocher JP, Subramanian S and Kalari KR: Circular RNAs and their associations with breast cancer subtypes. Oncotarget 7: 80967-80979, 2016.

26. Yao JT, Zhao SH, Liu QP, Lv MQ, Zhou DX, Liao ZJ and Nan KJ: Over-expression of CircRNA_100876 in non-small cell lung cancer and its prognostic value. Pathol Res Pract 213: 453-456, 2017.

27. Salzman J, Gawad C, Wang PL, Lacayo N and Brown PO: Circular RNAs are the predominant transcript isoform from hundreds of human genes in diverse cell types. PLoS One 7: e30733, 2012.

28. Dang Y, Ouyang X, Zhang F, Wang K, Lin Y, Sun B, Wang Y, Wang L and Huang Q: Circular RNAs expression profiles in human gastric cancer. Sci Rep 7: 9060, 2017.

29. Gu W, Sun Y, Zheng X, Ma J, Hu XY, Gao T and Hu MJ: Identification of gastric cancer-related circular RNA through microarray analysis and bioinformatics analysis. Biomed Res Int 2018: 2381680, 2018

30. Huang YS, Jie N, Zou KJ and Weng Y: Expression profile of circular RNAs in human gastric cancer tissues. Mol Med Rep 16: 2469-2476, 2017.

31. Sui W, Shi Z, Xue W, Ou M, Zhu Y, Chen J, Lin H, Liu F and Dai Y: Circular RNA and gene expression profiles in gastric cancer based on microarray chip technology. Oncol Rep 37: 1804-1814, 2017

32. Li T, Shao Y, Fu L, Xie Y, Zhu L, Sun W, Yu R, Xiao B and Guo J: Plasma circular RNA profiling of patients with gastric cancer and their droplet digital RT-PCR detection. J Mol Med (Berl) 96: 85-96, 2018

33. Li P, Chen S, Chen H, Mo X, Li T, Shao Y, Xiao B and Guo J: Using circular RNA as a novel type of biomarker in the screening of gastric cancer. Clin Chim Acta 444: 132-136, 2015.

34. Chen S, Li T, Zhao Q, Xiao B and Guo J: Using circular RNA hsa_circ_0000190 as a new biomarker in the diagnosis of gastric cancer. Clin Chim Acta 466: 167-171, 2017.

35. Tian M, Chen R, Li T and Xiao B: Reduced expression of circRNA hsa_circ_0003159 in gastric cancer and its clinical significance. J Clin Lab Anal 32: e22281, 2018.

36. Xie Y, Shao Y, Sun W, Ye G, Zhang X, Xiao B and Guo J: Downregulated expression of hsa_circ 0074362 in gastric cancer and its potential diagnostic values. Biomark Med 12: 11-20, 2018.

37. Huang M, He YR, Liang LC, Huang Q and Zhu ZQ: Circular RNA hsa_circ_0000745 may serve as a diagnostic marker for gastric cancer. World J Gastroenterol 23: 6330-6338, 2017.

38. Sun H, Tang W, Rong D, Jin H, Fu K, Zhang W, Liu Z, Cao H and Cao X: Hsa_circ_0000520, a potential new circular RNA biomarker, is involved in gastric carcinoma. Cancer Biomark 21: 299-306, 2018

39. Shao Y, Li J, Lu R, Li T, Yang Y, Xiao B and Guo J: Global circular RNA expression profile of human gastric cancer and its clinical significance. Cancer Med 6: 1173-1180, 2017.

40. Yamamichi N, Hirano C, Ichinose M, Takahashi Y, Minatsuki C, Matsuda R, Nakayama C, Shimamoto T, Kodashima S, Ono S, et al: Atrophic gastritis and enlarged gastric folds diagnosed by double-contrast upper gastrointestinal barium X-ray radiography are useful to predict future gastric cancer development based on the 3-year prospective observation. Gastric Cancer 19: 1016-1022, 2016.

41. Zhang Y, Liu H, Li W, Yu J, Li J, Shen Z, Ye G, Qi X and Li G: CircRNA_100269 is downregulated in gastric cancer and suppresses tumor cell growth by targeting miR-630. Aging (Albany NY) 9: 1585-1594,2017.

42. Zhang J, Liu H, Hou L, Wang G, Zhang R, Huang Y, Chen X and Zhu J: Circular RNA_LARP4 inhibits cell proliferation and invasion of gastric cancer by sponging miR-424-5p and regulating LATS1 expression. Mol Cancer 16: 151, 2017.

43. Chen J, Li Y, Zheng Q, Bao C, He J, Chen B, Lyu D, Zheng B, $\mathrm{Xu} \mathrm{Y}$, Long Z, et al: Circular RNA profile identifies circPVT1 as a proliferative factor and prognostic marker in gastric cancer. Cancer Lett 388: 208-219, 2017.

44. Cheng J, Zhuo H, Xu M, Wang L, Xu H, Peng J, Hou J, Lin L and Cai J: Regulatory network of circRNA-miRNA-mRNA contributes to the histological classification and disease progression in gastric cancer. J Transl Med 16: 216, 2018. 
45. Lai Z, Yang Y, Yan Y, Li T, Li Y, Wang Z, Shen Z, Ye Y, Jiang $K$ and Wang S: Analysis of co-expression networks for circular RNAs and mRNAs reveals that circular RNAs hsa circ_0047905, hsa_circ_0138960 and has-circRNA7690-15 are candidate oncogenes in gastric cancer. Cell Cycle 16: 2301-2311, 2017.

46. Shen F, Liu P, Xu Z, Li N, Yi Z, Tie X, Zhang Y and Gao L: CircRNA 001569 promotes cell proliferation through absorbing miR-145 in gastric cancer. J Biochem 165: 27-36, 2019.

47. Zhou LH, Yang YC, Zhang RY, Wang P, Pang MH and Liang LQ: CircRNA_0023642 promotes migration and invasion of gastric cancer cells by regulating EMT. Eur Rev Med Pharmacol Sci 22 2297-2303, 2018

48. Lu J, Zhang PY, Li P, Xie JW, Wang JB, Lin JX, Chen QY, Cao LL, Huang CM and Zheng CH: Circular RNA hsa_circ_0001368 suppresses the progression of gastric cancer by regulating miR-6506-5p/FOXO3 axis. Biochem Biophys Res Commun 512: 29-33, 2019.

49. Zhang X, Wang S, Wang H, Cao J, Huang X, Chen Z, Xu P, Sun G, Xu J, Lv J and Xu Z: Circular RNA circNRIP1 acts as a microRNA-149-5p sponge to promote gastric cancer progression via the AKT1/mTOR pathway. Mol Cancer 18: 20, 2019.

50. Rong D, Lu C, Zhang B, Fu K, Zhao S, Tang W and Cao H: CircPSMC3 suppresses the proliferation and metastasis of gastric cancer by acting as a competitive endogenous RNA through sponging miR-296-5p. Mol Cancer 18: 25, 2019.

51. Wang L, Shen J and Jiang Y: Circ_0027599/PHDLA1 suppresses gastric cancer progression by sponging miR-101-3p.1. Cell Biosci 8: 58, 2018.

52. Chen Y, Yang F, Fang E, Xiao W, Mei H, Li H, Li D, Song H, Wang J, Hong M, et al: Circular RNA circAGO2 drives cancer progression through facilitating HuR-repressed functions of AGO2-miRNA complexes. Cell Death Differ 26: 1346-1364, 2019.

53. Fang J, Hong H, Xue X, Zhu X, Jiang L, Qin M, Liang H and Gao L: A novel circular RNA, circFAT1(e2), inhibits gastric cancer progression by targeting miR-548g in the cytoplasm and interacting with YBX1 in the nucleus. Cancer Lett 442: 222-232, 2019.

54. Liu X, Abraham JM, Cheng Y, Wang Z, Wang Z, Zhang G, Ashktorab H, Smoot DT, Cole RN, Boronina TN, et al: Synthetic Circular RNA Functions as a miR-21 Sponge to suppress gastric carcinoma cell proliferation. Mol Ther Nucleic Acids 13: 312-321, 2018 .

55. Ouyang Y, Li Y, Huang Y, Li X, Zhu Y, Long Y, Wang Y, Guo X and Gong K: CircRNA circPDSS1 promotes the gastric cancer progression by sponging miR-186-5p and modulating NEK2 J Cell Physiol 234: 10458-10469, 2019.

56. Sun HD, Xu ZP, Sun ZQ, Zhu B, Wang Q, Zhou J, Jin H, Zhao A, Tang WW and Cao XF: Down-regulation of circPVRL3 promotes the proliferation and migration of gastric cancer cells. Sci Rep 8: 10111, 2018.

57. Sun H, Xi P, Sun Z, Wang Q, Zhu B, Zhou J, Jin H, Zheng W, Tang W, Cao H and Cao X: Circ-SFMBT2 promotes the proliferation of gastric cancer cells through sponging miR-182-5p to enhance CREB1 expression. Cancer Manag Res 10: 5725-5734, 2018.

58. Xu Y, Yao Y, Zhong X, Leng K, Qin W, Qu L, Cui Y and Jiang X: Downregulated circular RNA hsa_circ_0001649 regulates proliferation, migration and invasion in cholangiocarcinoma cells. Biochem Biophys Res Commun 496: 455-461, 2018.

59. Zhang H, Zhu L, Bai M, Liu Y, Zhan Y, Deng T, Yang H, Sun W, Wang X, Zhu K, et al: Exosomal circRNA derived from gastric tumor promotes white adipose browning by targeting the miR-133/PRDM16 pathway. Int J Cancer 144: 2501-2515, 2019.

60. Ding L, Zhao Y, Dang S, Wang Y, Li X, Yu X, Li Z, Wei J, Liu M and Li G: Circular RNA circ-DONSON facilitates gastric cancer growth and invasion via NURF complex dependent activation of transcription factor SOX4. Mol Cancer 18: 45, 2019.

61. Zhang J, Hou L, Liang R, Chen X, Zhang R, Chen W and Zhu J: CircDLST promotes the tumorigenesis and metastasis of gastric cancer by sponging miR-502-5p and activating the NRAS/MEK1/ERK1/2 signaling. Molecular Cancer 18: 80, 2019

62. Zhu Z, Rong Z, Luo Z, Yu Z, Zhang J, Qiu Z and Huang C: Circular RNA circNHSL1 promotes gastric cancer progression through the miR-1306-3p/SIX1/vimentin axis. Mol Cancer 18 : $126,2019$.

63. Zhang L, Song X, Chen X, Wang Q, Zheng X, Wu C and Jiang J: Circular RNA CircCACTIN promotes gastric cancer progression by Sponging MiR-331-3p and regulating TGFBR1 expression. Int J Biol Sci 15: 1091-1103, 2019.
64. Wang S, Zhang X, Li Z, Wang W, Li B, Huang X, Sun G, Xu J, Li Q, Xu Z, et al: Circular RNA profile identifies circOSBPL10 as an oncogenic factor and prognostic marker in gastric cancer. Oncogene 38: 6985-7001, 2019

65. Bartolomei MS, Zemel S and Tilghman SM: Parental imprinting of the mouse H19 gene. Nature 351: 153-155, 1991.

66. Gibb EA, Brown CJ and Lam WL: The functional role of long non-coding RNA in human carcinomas. Mol Cancer 10: 38, 2011

67. Huang X, Luo YL, Mao YS and Ji JL: The link between long noncoding RNAs and depression. Prog Neuropsychopharmacol Biol Psychiatry 73: 73-78, 2017.

68. Marin-Bejar O, Mas AM, Gonzalez J, Martinez D, Athie A, Morales X, Galduroz M, Raimondi I, Grossi E, Guo S, et al: The human lncRNA LINC-PINT inhibits tumor cell invasion through a highly conserved sequence element. Genome Biol 18: 202, 2017.

69. Neppl RL, Wu CL and Walsh K: lncRNA Chronos is an aging-induced inhibitor of muscle hypertrophy. J Cell Biol 216: 3497-3507, 2017

70. Rupaimoole R and Slack FJ: MicroRNA therapeutics: Towards a new era for the management of cancer and other diseases. Nat Rev Drug Discov 16: 203-222, 2017.

71. Peng WX, Koirala P and Mo YY: LncRNA-mediated regulation of cell signaling in cancer. Oncogene 36: 5661-5667, 2017.

72. Liu Y, Gonzalez-Porta M, Santos S, Brazma A, Marioni JC, Aebersold R, Venkitaraman AR and Wickramasinghe VO: Impact of alternative splicing on the human proteome. Cell Rep 20: 1229-1241, 2017.

73. Luco RF: Retrotransposons jump into alternative-splicing regulation via a long noncoding RNA. Nat Struct Mol Biol 23: 952-954, 2016.

74. Huang J, Zhang A, Ho TT, Zhang Z, Zhou N, Ding X, Zhang X, $\mathrm{Xu}$ M and Mo YY: Linc-RoR promotes c-Myc expression through hnRNP I and AUF1. Nucleic Acids Res 44: 3059-3069, 2016.

75. Li T, Mo X, Fu L, Xiao B and Guo J: Molecular mechanisms of long noncoding RNAs on gastric cancer. Oncotarget 7: 8601-8612, 2016

76. Mao Z, Li H, Du B, Cui K, Xing Y, Zhao X and Zai S: LncRNA DANCR promotes migration and invasion through suppression of lncRNA-LET in gastric cancer cells. Biosci Rep 37: BSR20171070, 2017.

77. Pan L, Liang W, Gu J, Zang X, Huang Z, Shi H, Chen J, Fu M, Zhang $\mathrm{P}$, Xiao X, et al: Long noncoding RNA DANCR is activated by SALL4 and promotes the proliferation and invasion of gastric cancer cells. Oncotarget 9: 1915-1930, 2017

78. Zhao L, Han T, Li Y, Sun J, Zhang S, Liu Y, Shan B, Zheng D and Shi J: The lncRNA SNHG5/miR-32 axis regulates gastric cancer cell proliferation and migration by targeting KLF4. FASEB J 31: 893-903, 2017

79. Zhu H, Zhao H, Zhang L, Xu J, Zhu C, Zhao $\mathrm{H}$ and Lv G: Dandelion root extract suppressed gastric cancer cells proliferation and migration through targeting lncRNA-CCAT1. Biomed Pharmacother 93: 1010-1017, 2017.

80. Li Y, Zhu G, Ma Y and Qu H: LncRNA CCAT1 contributes to the growth and invasion of gastric cancer via targeting miR-219-1. J Cell Biochem: Sep 3, 2019 (Epub ahead of print). doi: 10.1002/ jcb.29239.

81. Zhang J and Gao Y: CCAT-1 promotes proliferation and inhibits apoptosis of cervical cancer cells via the Wnt signaling pathway. Oncotarget 8: 68059-68070, 2017.

82. Du L, Duan W, Jiang X, Zhao L, Li J, Wang R, Yan S, Xie Y, Yan K, Wang Q, et al: Cell-free lncRNA expression signatures in urine serve as novel non-invasive biomarkers for diagnosis and recurrence prediction of bladder cancer. J Cell Mol Med 22: 2838-2845, 2018.

83. Si Y, Bai J, Wu J, Li Q, Mo Y, Fang R and Lai W: LncRNA PlncRNA1 regulates proliferation and differentiation of hair follicle stem cells through TGF $\beta 1$-mediated Wnt/ $\beta$-catenin signal pathway. Mol Med Rep 17: 1191-1197, 2018.

84. Yang Y, Shao Y, Zhu M, Li Q, Yang F, Lu X, Xu C, Xiao B, Sun Y and Guo J: Using gastric juice lncRNA-ABHD11-AS1 as a novel type of biomarker in the screening of gastric cancer. Tumour Biol 37: 1183-1188, 2016.

85. Clark MB, Johnston RL, Inostroza-Ponta M, Fox AH, Fortini E, Moscato P, Dinger ME and Mattick JS: Genome-wide analysis of long noncoding RNA stability. Genome Res 22: 885-898, 2012.

86. Sun W, Wu Y, Yu X, Liu Y, Song H, Xia T, Xiao B and Guo J: Decreased expression of long noncoding RNA AC096655.1-002 in gastric cancer and its clinical significance. Tumour Biol 34: $2697-2701,2013$ 
87. Lin X, Yang M, Xia T and Guo J: Increased expression of long noncoding RNA ABHD11-AS1 in gastric cancer and its clinical significance. Med Oncol 31: 42, 2014.

88. Baratieh Z, Khalaj Z, Honardoost MA, Emadi-Baygi M, Khanahmad H, Salehi M and Nikpour P: Aberrant expression of PlncRNA-1 and TUG1: Potential biomarkers for gastric cancer diagnosis and clinically monitoring cancer progression. Biomark Med 11: 1077-1090, 2017.

89. Dong L, Qi P, Xu MD, Ni SJ, Huang D, Xu QH, Weng WW, Tan C, Sheng WQ, Zhou XY and Du X: Circulating CUDR, LSINCT-5 and PTENP1 long noncoding RNAs in sera distinguish patients with gastric cancer from healthy controls. Int J Cancer 137: 1128-1135, 2015.

90. Hu QY, Zhao ZY, Li SQ, Li L and Li GK: A meta-analysis: The diagnostic values of long non-coding RNA as a biomarker for gastric cancer. Mol Clin Oncol 6: 846-852, 2017.

91. Hashad D, Elbanna A, Ibrahim A and Khedr G: Evaluation of the role of circulating long non-coding RNA H19 as a promising novel biomarker in plasma of patients with gastric cancer. J Clin Lab Anal 30: 1100-1105, 2016.

92.Elsayed ET, Salem PE, Darwish AM and Fayed HM: Plasma long non-coding RNA HOTAIR as a potential biomarker for gastric cancer. Int J Biol Markers: Apr 1, 2018 (Epub ahead of print). doi: $10.1177 / 1724600818760244$.

93. Zhou X, Yin C, Dang Y, Ye F and Zhang G: Identification of the long non-coding RNA H19 in plasma as a novel biomarker for diagnosis of gastric cancer. Sci Rep 5: 11516, 2015.

94.Zhang K, Shi H, Xi H, Wu X, Cui J, Gao Y, Liang W, Hu C, Liu Y, Li J, et al: Genome-Wide lncRNA microarray profiling identifies novel circulating lncRNAs for detection of gastric cancer. Theranostics 7: 213-227, 2017.

95. Li Q, Shao Y, Zhang X, Zheng T, Miao M, Qin L, Wang B, Ye G, Xiao B and Guo J: Plasma long noncoding RNA protected by exosomes as a potential stable biomarker for gastric cancer. Tumour Biol 36: 2007-2012, 2015.

96.Zheng Q, Wu F, Dai WY, Zheng DC, Zheng C, Ye H, Zhou B, Chen JJ and Chen P: Aberrant expression of UCA1 in gastric cancer and its clinical significance. Clin Transl Oncol 17: 640-646, 2015.

97. Shao Y, Ye M, Jiang X, Sun W, Ding X, Liu Z, Ye G, Zhang X, Xiao B and Guo J: Gastric juice long noncoding RNA used as a tumor marker for screening gastric cancer. Cancer 120: 3320-3328, 2014

98. Shao Y, Ye M, Li Q, Sun W, Ye G, Zhang X, Yang Y, Xiao B and Guo J: LncRNA-RMRP promotes carcinogenesis by acting as a miR-206 sponge and is used as a novel biomarker for gastric cancer. Oncotarget 7: 37812-37824, 2016.

99. Pang Q, Ge J, Shao Y, Sun W, Song H, Xia T, Xiao B and Guo J: Increased expression of long intergenic non-coding RNA LINC00152 in gastric cancer and its clinical significance. Tumour Biol 35: 5441-5447, 2014.

100. Fei ZH, Yu XJ, Zhou M, Su HF, Zheng Z and Xie CY: Upregulated expression of long non-coding RNA LINC00982 regulates cell proliferation and its clinical relevance in patients with gastric cancer. Tumour Biol 37: 1983-1993, 2016.

101. Chen JS, Wang YF, Zhang XQ, Lv JM, Li Y, Liu XX and Xu TP: H19 serves as a diagnostic biomarker and up-regulation of H19 expression contributes to poor prognosis in patients with gastric cancer. Neoplasma 63: 223-230, 2016.

102. Hunt RH, Xiao SD, Megraud F, Leon-Barua R, Bazzoli F, van der Merwe S, Vaz Coelho LG, Fock M, Fedail S, Cohen $\mathrm{H}$, et al: Helicobacter pylori in developing countries. World gastroenterology organisation global guideline. J Gastrointestin Liver Dis 20: 299-304, 2011.

103. Amieva $\mathrm{M}$ and Peek RM Jr: Pathobiology of Helicobacter pylori-induced gastric cancer. Gastroenterology 150: 64-78, 2016.

104. Zhong F, Zhu M, Gao K, Xu P, Yang H, Hu D, Cui D, Wang M, Xie X, Wei Y, et al: Low expression of the long non-coding RNA NR_026827 in gastric cancer. Am J Transl Res 10: 2706-2711, 2018 .

105. Lu Q, Yu T, Ou X, Cao D, Xie T and Chen X: Potential lncRNA diagnostic biomarkers for early gastric cancer. Mol Med Rep 16: 9545-9552, 2017.

106. Du M, Wang W, Jin H, Wang Q, Ge Y, Lu J, Ma G, Chu H, Tong $\mathrm{N}$, Zhu $\mathrm{H}$, et al: The association analysis of lncRNA HOTAIR genetic variants and gastric cancer risk in a Chinese population. Oncotarget 6: 31255-31262, 2015.

107. Liu JN and Shangguan YM: Long non-coding RNA CARLo-5 upregulation associates with poor prognosis in patients suffering gastric cancer. Eur Rev Med Pharmacol Sci 21: 530-534, 2017.
108. Feng Y, Zhang Q, Wang J and Liu P: Increased lncRNA AFAP1-AS1 expression predicts poor prognosis and promotes malignant phenotypes in gastric cancer. Eur Rev Med Pharmacol Sci 21: 3842-3849, 2017.

109. Li L, Geng Y, Feng R, Zhu Q, Miao B, Cao J and Fei S: The human RNA surveillance factor UPF1 modulates gastric cancer progression by targeting long non-coding RNA MALAT1. Cell Physiol Biochem 42: 2194-2206, 2017.

110. Li Y, Wen X, Wang L, Sun X, Ma H, Fu Z and Li L: LncRNA ZEB1-AS1 predicts unfavorable prognosis in gastric cancer. Surg Oncol 26: 527-534, 2017.

111. Ma P, Xu T, Huang M and Shu Y: Increased expression of LncRNA PANDAR predicts a poor prognosis in gastric cancer. Biomed Pharmacother 78: 172-176, 2016.

112. Yao XM, Tang JH, Zhu H and Jing Y: High expression of LncRNA CASC15 is a risk factor for gastric cancer prognosis and promote the proliferation of gastric cancer. Eur Rev Med Pharmacol Sci 21: 5661-5667, 2017.

113. Xia H, Chen Q, Chen Y, Ge X, Leng W, Tang Q, Ren M, Chen L, Yuan D, Zhang Y, et al: The lncRNA MALAT1 is a novel biomarker for gastric cancer metastasis. Oncotarget 7: 56209-56218, 2016.

114. Zhu X, Tian X, Yu C, Shen C, Yan T, Hong J, Wang Z, Fang JY and Chen $\mathrm{H}$ : A long non-coding RNA signature to improve prognosis prediction of gastric cancer. Mol Cancer 15: 60, 2016.

115. Chen Y, Wei G, Xia H, Tang Q and Bi F: Long noncoding RNA-ATB promotes cell proliferation, migration and invasion in gastric cancer. Mol Med Rep 17: 1940-1946, 2018.

116. $\mathrm{Li} \mathrm{CH}$ and Chen $\mathrm{Y}$ : Targeting long non-coding RNAs in cancers: Progress and prospects. Int J Biochem Cell Biol 45: 1895-1910, 2013.

117. Ransohoff JD, Wei Y and Khavari PA: The functions and unique features of long intergenic non-coding RNA. Nat Rev Mol Cell Biol 19: 143-157, 2018

118. Dong X, He X, Guan A, Huang W, Jia H, Huang Y, Chen S, Zhang Z, Gao J and Wang H: Long non-coding RNA Hotair promotes gastric cancer progression via miR-217-GPC5 axis. Life Sci 217: 271-282, 2019.

119. Song B, Guan Z, Liu F, Sun D, Wang K and Qu H: Long non-coding RNA HOTAIR promotes HLA-G expression via inhibiting miR-152 in gastric cancer cells. Biochem Biophys Res Commun 464: 807-813, 2015.

120. Jiang D, Li H, Xiang H, Gao M, Yin C, Wang H, Sun Y and Xiong M: Long chain non-coding RNA (lncRNA) HOTAIR knockdown increases miR-454-3p to suppress gastric cancer growth by targeting STAT3/Cyclin D1. Med Sci Monit 25: 1537-1548, 2019.

121. Jia J, Zhan D, Li J, Li Z, Li H and Qian J: The contrary functions of lncRNA HOTAIR/miR-17-5p/PTEN axis and Shenqifuzheng injection on chemosensitivity of gastric cancer cells. J Cell Mol Med 23: 656-669, 2019

122. Lotem J, Levanon D, Negreanu V, Bauer O, Hantisteanu S, Dicken J and Groner Y: Runx3 in immunity, inflammation and cancer. Adv Exp Med Biol 962: 369-393, 2017.

123. Xue M, Chen LY, Wang WJ, Su TT, Shi LH, Wang L, Zhang W, Si JM, Wang LJ and Chen SJ: HOTAIR induces the ubiquitination of Runx3 by interacting with Mex3b and enhances the invasion of gastric cancer cells. Gastric Cancer 21: 756-764, 2018.

124.Zeng S, Xie X, Xiao YF, Tang B, Hu CJ, Wang SM, Wu YY, Dong H, Li BS and Yang SM: Long noncoding RNA LINC00675 enhances phosphorylation of vimentin on Ser83 to suppress gastric cancer progression. Cancer Lett 412: 179-187, 2018.

125. Li D, Yang M, Liao A, Zeng B, Liu D, Yao Y, Hu G, Chen X, Feng Z, Du Y, et al: Linc00483 as ceRNA regulates proliferation and apoptosis through activating MAPKs in gastric cancer. J Cell Mol Med 22: 3875-3886, 2018

126. Shan Y, Ying R, Jia Z, Kong W, Wu Y, Zheng S and Jin H: LINC00052 promotes gastric cancer cell proliferation and metastasis via activating the $\mathrm{Wnt} / \beta$-catenin signaling pathway. Oncol Res 25: 1589-1599, 2017.

127. Zhou J, Zhi X, Wang L, Wang W, Li Z, Tang J, Wang J, Zhang Q and $\mathrm{Xu} \mathrm{Z}$ : Linc 00152 promotes proliferation in gastric cancer through the EGFR-dependent pathway. J Exp Clin Cancer Res 34: 135, 2015.

128. Yan J, Zhang Y, She Q, Li X, Peng L, Wang X, Liu S, Shen X, Zhang W, Dong Y, et al: Long noncoding RNA H19/miR-675 axis promotes gastric cancer via FADD/Caspase 8/Caspase 3 signaling pathway. Cell Physiol Biochem 42: 2364-2376, 2017. 
129. Marin JJ, Al-Abdulla R, Lozano E, Briz O, Bujanda L, Banales JM and Macias RI: Mechanisms of resistance to chemotherapy in gastric cancer. Anticancer Agents Med Chem 16: 318-334, 2016

130. Zhang X, Bo P, Liu L, Zhang X and Li J: Overexpression of long non-coding RNA GHET1 promotes the development of multidrug resistance in gastric cancer cells. Biomed Pharmacother 92 580-585, 2017.

131. Lan WG, Xu DH, Xu C, Ding CL, Ning FL, Zhou YL, Ma LB, Liu CM and Han X: Silencing of long non-coding RNA ANRIL inhibits the development of multidrug resistance in gastric cancer cells. Oncol Rep 36: 263-270, 2016.

132.Xi Z, Si J and Nan J: LncRNA MALAT1 potentiates autophagyassociated cisplatin resistance by regulating the microRNA30b/autophagyrelated gene 5 axis in gastric cancer. Int J Oncol 54: 239-248, 2019

133. Li Y, Lv S, Ning H, Li K, Zhou X, Xv H and Wen $\mathrm{H}$ : Down-regulation of CASC2 contributes to cisplatin resistance in gastric cancer by sponging miR-19a. Biomed Pharmacother 108: 1775-1782, 2018.

134. Fang Q, Chen X and Zhi X: Long non-coding RNA (LncRNA) urothelial carcinoma associated 1 (UCA1) increases multi-drug resistance of gastric cancer via downregulating miR-27b. Med Sci Monit 22: 3506-3513, 2016.

135. Shang C, Guo Y, Zhang J and Huang B: Silence of long noncoding RNA UCA1 inhibits malignant proliferation and chemotherapy resistance to adriamycin in gastric cancer. Cancer Chemother Pharmacol 77: 1061-1067, 2016.

136. Thorburn A: Autophagy and disease. J Biol Chem 293: 5425-5430, 2018.

137. Li YJ, Lei YH, Yao N, Wang CR, Hu N, Ye WC, Zhang DM and Chen ZS: Autophagy and multidrug resistance in cancer. Chin J Cancer 36: 52, 2017.

138. YiRen H, YingCong Y, Sunwu Y, Keqin L, Xiaochun T, Senrui C, Ende C, XiZhou L and Yanfan C: Long noncoding RNA MALAT1 regulates autophagy associated chemoresistance via miR-23b-3p sequestration in gastric cancer. Mol Cancer 16: 174, 2017.

139. Suresh PS, Tsutsumi R and Venkatesh T: YBX1 at the crossroads of non-coding transcriptome, exosomal, and cytoplasmic granular signaling. Eur J Cell Biol 97: 163-167, 2018.

140. Zhang E, He X, Zhang C, Su J, Lu X, Si X, Chen J, Yin D, Han L and De W: A novel long noncoding RNA HOXC-AS3 mediates tumorigenesis of gastric cancer by binding to YBX1. Genome Biol 19: 154, 2018.

141. Liu Y, Zhao J, Zhang W, Gan J, Hu C, Huang G and Zhang Y: lncRNA GAS5 enhances $\mathrm{G} 1$ cell cycle arrest via binding to YBX1 to regulate p21 expression in stomach cancer. Sci Rep 5: 10159,2015

142. Chen WM, Chen WD, Jiang XM, Jia XF, Wang HM, Zhang QJ, Shu YQ and Zhao HB: HOX transcript antisense intergenic RNA represses E-cadherin expression by binding to EZH2 in gastric cancer. World J Gastroenterol 23: 6100-6110, 2017.

143. Qi Y, Ooi HS, Wu J, Chen J, Zhang X, Tan S, Yu Q, Li YY, Kang Y, $\mathrm{LiH}$, et al: MALAT1 long ncRNA promotes gastric cancer metastasis by suppressing PCDH10. Oncotarget 7: 12693-12703, 2016.

144. Wang ZQ, Cai Q, Hu L, He CY, Li JF, Quan ZW, Liu BY, Li C and Zhu ZG: Long noncoding RNA UCA1 induced by SP1 promotes cell proliferation via recruiting EZH2 and activating AKT pathway in gastric cancer. Cell Death Dis 8: e2839, 2017.

145. Ba MC, Long H, Cui SZ, Gong YF, Yan ZF, Wu YB and Tu YN Long noncoding RNA LINC00673 epigenetically suppresses KLF4 by interacting with EZH2 and DNMT1 in gastric cancer. Oncotarget 8: 95542-95553, 2017.
146. Milane L, Singh A, Mattheolabakis G, Suresh M and Amiji MM Exosome mediated communication within the tumor microenvironment. J Control Release 219: 278-294, 2015.

147. Vlassov AV, Magdaleno S, Setterquist R and Conrad R: Exosomes: Current knowledge of their composition, biological functions, and diagnostic and therapeutic potentials. Biochim Biophys Acta 1820: 940-948, 2012

148. Rajagopal C and Harikumar KB: The origin and functions of exosomes in cancer. Front Oncol 8: 66, 2018

149. Pan L, Liang W, Fu M, Huang ZH, Li X, Zhang W, Zhang P, Qian H, Jiang PC, Xu WR and Zhang X: Exosomes-mediated transfer of long noncoding RNA ZFAS1 promotes gastric cancer progression. J Cancer Res Clin Oncol 143: 991-1004, 2017.

150. Lin LY, Yang L, Zeng Q, Wang L, Chen ML, Zhao ZH, Ye GD, Luo QC, Lv PY, Guo QW, et al: Tumor-originated exosomal lncUEGC1 as a circulating biomarker for early-stage gastric cancer. Mol Cancer 17: 84, 2018.

151. Zhao R, Zhang Y, Zhang X, Yang Y, Zheng X, Li X, Liu Y and Zhang Y: Exosomal long noncoding RNA HOTTIP as potential novel diagnostic and prognostic biomarker test for gastric cancer. Mol Cancer 17: 68, 2018.

152. Tang W, Fu K, Sun H, Rong D, Wang H and Cao H: CircRNA microarray profiling identifies a novel circulating biomarker for detection of gastric cancer. Mol Cancer 17: 137, 2018.

153. Shao Y, Tao X, Lu R, Zhang H, Ge J, Xiao B, Ye G and Guo J: Hsa_circ_0065149 is an indicator for early gastric cancer screening and prognosis prediction. Pathol Oncol Res 26: $1475-1482,2019$.

154. Huang T, Liu HW, Chen JQ, Wang SH, Hao LQ, Liu M and Wang B: The long noncoding RNA PVT1 functions as a competing endogenous RNA by sponging miR-186 in gastric cancer. Biomed Pharmacother 88: 302-308, 2017.

155. Li LJ, Leng RX, Fan YG, Pan HF and Ye DQ: Translation of noncoding RNAs: Focus on lncRNAs, pri-miRNAs, and circRNAs. Exp Cell Res 361: 1-8, 2017.

156. Gulmann C, Hegarty H, Grace A, Leader M, Patchett S and Kay E: Differences in proximal (cardia) versus distal (antral) gastric carcinogenesis via the retinoblastoma pathway. World J Gastroenterol 10: 17-21, 2004.

157. Pan Z, Li GF, Sun ML, Xie L, Liu D, Zhang Q, Yang XX, Xia S, Liu X, Zhou H, et al: MicroRNA-1224 splicing circularRNA-Filip1l in an Ago2-Dependent manner regulates chronic inflammatory pain via targeting Ubr5. J Neurosci 39: 2125-2143, 2019

158. Du M, Yuan L, Tan X, Huang D, Wang X, Zheng Z, Mao X, Li X, Yang L, Huang K, et al: The LPS-inducible lncRNA Mirt2 is a negative regulator of inflammation. Nat Commun 8: 2049, 2017.

159. Coon SL, Munson PJ, Cherukuri PF, Sugden D, Rath MF, Møller M, Clokie SJ, Fu C, Olanich ME, Rangel Z, et al: Circadian changes in long noncoding RNAs in the pineal gland. Proc Natl Acad Sci USA 109: 13319-13324, 2012.

160. Zhao Y, Alexandrov PN, Jaber V and Lukiw WJ: Deficiency in the ubiquitin conjugating enzyme UBE2A in Alzheimer's disease (AD) is linked to deficits in a natural circular miRNA-7 Sponge (circRNA; ciRS-7). Genes (Basel) 7: 116, 2016.

161. Guo H, Liu J, Ben Q, Qu Y, Li M, Wang Y, Chen W and Zhang J: The aspirin-induced long non-coding RNA OLA1P2 blocks phosphorylated STAT3 homodimer formation. Genome Biol 17: 24,2016

This work is licensed under a Creative Commons Attribution-NonCommercial-NoDerivatives 4.0 International (CC BY-NC-ND 4.0) License. 